\title{
Effects of conjugated linoleic acid supplementation on growth, carcass characteristics and fatty acid profiles of muscle and fat in growing-finishing pigs*
}

\author{
X.F. Han 1,5, F.J. Feng ${ }^{2,5}$, J.P. Yu ${ }^{2}$, S.X. Tang ${ }^{1}$, M.A. Bamikole, \\ Z.L. Tan ${ }^{1,4}$, B. Zeng ${ }^{1}$, C.S. Zhou ${ }^{1}$ and M. Wang ${ }^{1}$ \\ ${ }^{1}$ Key Laboratory of Agro-ecological Processes in Subtropical Region, \\ Institute of Subtropical Agriculture, Chinese Academy of Sciences \\ Hunan 410125, P.R. China \\ ${ }^{2}$ Research Center for Land Surface Systems, \\ Institute of Geographical Sciences and Natural Resources Research, \\ Chinese Academy of Sciences \\ Beijing 100101, P.R. China \\ ${ }^{3}$ University of Benin, Department of Animal Science, Faculty of Agriculture \\ Benin City, PMB 1154, Edo State, Nigeria
}

(Received 1 March 2011; revised version 6 April 2011; accepted 18 June 2011)

\begin{abstract}
This study investigated the effects of dietary supplementation of conjugated linoleic acid (CLA) on the growth performance, carcass characteristics, muscle quality and fatty acid compositions in the skeletal muscle and backfat of growing-finishing pigs from 39.5 to $108.0 \mathrm{~kg}$. Forty-eight pigs were randomly allotted to four diets containing 0 (control), $0.5,1.0$ or $1.5 \%$ of CLA mixture (35.2\% cis-9, trans-11 and $37.5 \%$ trans-10, cis-12) for 12 weeks. The results showed that dietary CLA supplementation did not affect the animal's growth performance and carcass characteristics, whereas significantly increased dry matter content of the Longissimus dorsi muscle $(\mathrm{P}<0.05)$. The CLA supplementation also increased the content of saturated fatty acids, but decreased $(\mathrm{P}<0.05)$ the content of unsaturated fatty acids (UFA) in both the backfat and Longissimus dorsi muscle. The CLA concentrations in the Longissimus dorsi muscle and backfat were increased linearly by the CLA supplementation in a dose-dependent manner. However, CLA cis-9, trans-11 and CLA trans10, cis-12 showed different deposition efficiencies in pigs.
\end{abstract}

\footnotetext{
"Supported by Hunan Science and Technology Major Projects, Grant No. 2009FJ1005, and the Knowledge Innovation Program (KIP) Important Projects of The Chinese Academy of Science, Grants No. KSCX-YW-N-49 and KZCX2-YW-T07

${ }^{4}$ Corresponding author: e-mail: zltan@isa.ac.cn

${ }^{5}$ The authors wish it to be known that, the first two authors should be regarded as joint First Authors
} 
KEY WORDS: conjugated linoleic acid, carcass characteristics, fatty acids, pigs

\section{INTRODUCTION}

Conjugated linoleic acid (CLA) refers to a group of positional and geometric (cis or trans) isomers of linoleic acid. It has been initially isolated and identified as an anticarcinogenic agent from fried ground beef (Ha et al., 1987). In recent years, CLA has been reported to have a wide range of biologically beneficial effects, including anticarcinogenic, antiobesity, antiatherogenic and immunomodulatory functions, and lean body mass promotion (Azain, 2003; Pariza, 2004; Bhattacharya et al., 2006).

Food products derived from ruminants are the richest natural sources of CLA (Tanaka, 2005). Researchers have demonstrated that dietary alterations of both ruminant and non-ruminant animals could increase the unsaturated fatty acid and CLA levels of meat, thereby improve its potential health benefits (Boles et al., 2005). The only plausible way to increase muscle CLA content effectively would be to provide chemically synthesized CLA as a dietary supplement in pigs (Joo et al., 2002). Thus, feeding pigs with CLA has been suggested as a potential strategy for obtaining meat products enriched with CLA (Schmid et al., 2006).

An important issue is the effect of dietary CLA on growth traits and fatty acid profiles. However, the results on this issue are inconsistent. Some researchers have shown the improvement in growth rate and carcass traits of pigs when fed diets enriched in CLA (Thiel-Cooper et al., 2001; Weber et al., 2006), but other studies did not find any significant responses (Ramsay et al., 2001; Tischendorf et al., 2002; Corino et al., 2003). On the other hand, few studies on the effects of dietary CLA on growth performance and fatty acids compositions have been conducted in pigs throughout grow-finish phase.

Thus, the present study was therefore designed to evaluate the influence of dietary levels of CLA supplementation on growth rate, carcass characteristics and fatty acid profiles in skeletal muscle and subcutaneous fat, and to determinate the optimum dietary CLA dose for growing-finishing pigs.

\section{MATERIAL AND METHODS}

\section{Animals and diets}

The use of the animals and the experimental procedure was approved by the Animal Welfare Committee of the Institute of Subtropical Agriculture, the Chinese Academy of Sciences. 
Forty-eight Landrace $\times$ Large White pigs with the initial weight of $39.5 \pm 1.7$ $\mathrm{kg}$ were used for the study and randomly assigned to four dietary treatments in 12 animals with each. The animals were housed in individual pens, four piglets per pen (two barrows and two gilts in each pen), so each treatment had triplicates. Fresh water was accessed ad libitum (nipple drinkers).

The basal diet was composed to meet the nutrient requirements according the NRC (1998) standard and was purchased from a commercial feed company (Liuhe Ltd., Qingdao, China). Chemical composition and nutrient contents of the basal diet are shown in Table 1. The four diets were prepared by the basal diet supplemented with four levels of CLA $(0.0,0.5,1.0$ and 1.5\%) (Institute of Geographic Sciences and Natural Resources Research, CAS, China). The CLA compound contained $72.7 \%$ CLA isomers $(35.2 \%$ of cis -9 , trans -11 and $37.5 \%$ of trans-10, cis-12 isomers).

Table 1. Ingredients and chemical composition of the basal diet

\begin{tabular}{lc}
\hline Item & $\%$ \\
\hline Ingredients & 65.2 \\
maize & 21.0 \\
soyabean meal & 11.0 \\
wheat bran & 0.8 \\
powdered limestone & 1.2 \\
dicalcium phosphate & 0.4 \\
salt & 0.4 \\
vitamin and mineral premix & \\
Chemical composition & 86.0 \\
dry matter & 15.0 \\
crude protein & 3.1 \\
crude fat & 8.0 \\
crude fibre & 8.0 \\
ash & 0.7 \\
calcium & 0.4 \\
phosphorus & 0.8 \\
lysine & \\
\hline
\end{tabular}

The animals were fed twice at 08.00 and 18.00. The whole experimental period lasted for 13 weeks, consisting of one week of adaptation and 12 weeks of feeding period. Individual liveweight of pigs was recorded at the end of the experiment and used to calculate daily weight gain (ADG) over the experimental period. Pigs were slaughtered when their average weight reached $108 \mathrm{~kg}$.

\section{Sample collection and chemical analysis}

At the end of the experiment, two animals (one barrow and one gilt) from each 
pen were randomly selected for slaughter, thus there were six animals slaughtered for each treatment. Pigs were electrically stunned and followed exsanguinations. The carcass was scalded, for easy removal of hair, and then eviscerated. Hot carcass weight was recorded. The dressing percentage was calculated as hot carcass weight as a percentage of the final liveweight.

The left loin starting at the third from last thoracic vertebra and extending back to $30 \mathrm{~cm}$ was removed from the carcass within $0.5 \mathrm{~h}$ post slaughter, and taken to the laboratory immediately. The M. longissimus dorsi sample was taken to measure chemical composition: dry matter, ash, crude protein and crude fat (ether extract); the analyses were performed according to AOAC (2000) methods.

Samples of subcutaneous backfat and Longissimus dorsi muscle of about $10 \mathrm{~cm}$ length ended at the third from last thoracic vertebra on the left side of the carcass were taken, frozen in liquid $\mathrm{N}_{2}$, and stored at $-80^{\circ} \mathrm{C}$ for fatty acid analysis. On the analysis the samples of the muscle (about $2 \mathrm{~g}$ ) and backfat (about $1 \mathrm{~g}$ ) were hemogenated. Then $10 \mathrm{ml}$ of extraction solution (chloroform:methanol, $1: 1, \mathrm{vol} / \mathrm{vol}$ ) and $3 \mathrm{ml}$ distilled water were added and the extraction was allowed for $2 \mathrm{~h}$ at room temperature. After vacuum filtration, the residue was rinsed with $10 \mathrm{ml}$ of chloroform and then filtered again. The filtered solution was pooled and centrifuged at $5500 \mathrm{~g}$ for $10 \mathrm{~min}$. The upper layer (methanol and water layer) was removed and the bottom layer (chloroform layer containing lipid extracts) was sucked into a test tube. The tube was placed in a water bath at $37^{\circ} \mathrm{C}$ for evaporating chloroform under nitrogen stream. Then the extract was stored at $-40^{\circ} \mathrm{C}$ until analysis of fatty acids.

Fatty acids in the extract were analysed as fatty acid methyl esters (FAME) by gas chromatography. Briefly, $2 \mathrm{mg}$ of the extract was placed in a glass vial, and then $1.5 \mathrm{ml}$ hexane, $100 \mu \mathrm{l}$ methyl acetate and $100 \mu \mathrm{l}$ sodium methoxide were added in order, and thoroughly mixed. The mixture was kept for $20 \mathrm{~min}$ at $20^{\circ} \mathrm{C}$, and then $10 \mathrm{~min}$ at $-20^{\circ} \mathrm{C}$ in a refrigerator. Afterward, $60 \mu 1$ of oxalic acid was added quickly, and the vial was vortexed. After centrifuging at $5500 \mathrm{~g}$ for 10 min the supernatant was added with $\mathrm{Na}_{2} \mathrm{SO}_{4}$ to absorb moisture and stored for gas chromatography analysis.

The FAMEs was analysed by using an Agilent $6890 \mathrm{~N}$ gas chromatographer, equipped with a flame ionization detector (Agilent Technologies, Palo Alto, CA, USA). A CP-Sil 88 fused silica open tubular capillary column $(100 \mathrm{~m} \times 0.25 \mathrm{~nm})$ (Chrompack, Bridgewater, NJ, USA) was used. The oven temperature started at $45^{\circ} \mathrm{C}$ for $4 \mathrm{~min}$, thereafter, it was raised to $175^{\circ} \mathrm{C}$ at $13^{\circ} \mathrm{C} / \mathrm{min}$, held at $175^{\circ} \mathrm{C}$ for $27 \mathrm{~min}$ and then increased to $215^{\circ} \mathrm{C}$ at $4^{\circ} \mathrm{C} / \mathrm{min}$ and then held at $215^{\circ} \mathrm{C}$ for $35 \mathrm{~min}$.

The injector and detector temperatures were set at $250^{\circ} \mathrm{C}$. Carrier gas was hydrogen at a flow rate of $30 \mathrm{ml} / \mathrm{min}$. Identification of individual FAMEs was 
accomplished by the retention times of an authentic standard. Four specific isomers of CLA (cis-9, trans-11; trans-10, cis-12; cis-9, cis-11; and trans-9, trans-11; Matreya LLC, USA) were identified. The concentration of individual fatty acids was quantitated according the peak area, and expressed as proportion to total fatty acids detected.

\section{Statistical analysis}

Statistical analysis of experimental data was performed by using the GLM procedure of SAS (1999). Dietary treatment was treated as a factor. For growth rate of pigs, there were three replicates (i.e. three pens). As for carcass traits and fatty acids, there were six replicates which came from six pigs slaughtered. Significant level of the treatment was set $\mathrm{P}<0.05$, and significance of differences between the treatment means was tested using Duncan's test. A contrast analysis was also done to compare the linear (L) or quadratic (Q) response to CLA inclusion levels.

\section{RESULTS AND DISCUSSION}

Animal's growth performance, carcass traits and chemical composition of Longissimus dorsi muscle are shown in Table 2. The average feed intake and ADG were not affected by the inclusion of CLA ( $>>0.05)$. Similarly, Ramsay et al. (2001), Tischendorf et al. (2002) and Weber et al. (2006) found average daily gain of pigs was not influenced by feeding CLA. On the contrary, Thiel-Cooper et al. (2001) reported a linear increase in average daily gain in response to the level of CLA in the diet.

Table 2. Effects of dietary CLA supplementation on average daily gain, carcass characteristics, chemical composition of Longissimus dorsi muscle

\begin{tabular}{|c|c|c|c|c|c|c|c|c|}
\hline \multirow{3}{*}{ Item } & \multicolumn{4}{|c|}{ Dietary treatments } & \multirow{3}{*}{ SEM } & \multirow{3}{*}{$\mathrm{P}$} & \multicolumn{2}{|c|}{ Contrasts } \\
\hline & \multicolumn{4}{|c|}{ CLA, $\%$} & & & & \\
\hline & 0 & 0.5 & 1.0 & 1.5 & & & linear & quadratic \\
\hline Initial liveweight, kg & 39.6 & 39.4 & 39.7 & 39.4 & 1.228 & 0.997 & 0.941 & 0.944 \\
\hline Final liveweight, kg & 104.6 & 103.7 & 97.8 & 101.7 & 4.461 & 0.712 & 0.471 & 0.594 \\
\hline Feed intake, $\mathrm{kg} / \mathrm{d}$ & 1.84 & 1.97 & 1.87 & 1.84 & 0.062 & 0.461 & 0.776 & 0.254 \\
\hline Average daily gain, $\mathrm{kg} / \mathrm{d}$ & 0.76 & 0.71 & 0.65 & 0.69 & 0.049 & 0.453 & 0.221 & 0.377 \\
\hline Hot carcass weight, $\mathrm{kg}$ & 76.8 & 78.4 & 74.4 & 76.3 & 3.545 & 0.885 & 0.744 & 0.972 \\
\hline Dressing percentage & 73.4 & 75.6 & 76.1 & 75.1 & 0.851 & 0.174 & 0.158 & 0.083 \\
\hline \multicolumn{9}{|c|}{ Chemical compositions of fresh meat, \% } \\
\hline dry matter & $30.8^{\mathrm{b}}$ & $36.1^{\mathrm{a}}$ & $31.7^{\mathrm{b}}$ & $36.5^{\mathrm{a}}$ & 1.489 & 0.022 & 0.070 & 0.876 \\
\hline crude protein & 27.9 & 30.8 & 27.4 & 31.2 & 1.459 & 0.177 & 0.327 & 0.782 \\
\hline ether extract & 2.57 & 3.61 & 2.66 & 4.08 & 0.531 & 0.159 & 0.148 & 0.731 \\
\hline ash & 1.25 & 1.45 & 1.27 & 1.40 & 0.080 & 0.2403 & 0.492 & 0.642 \\
\hline
\end{tabular}


The hot carcass weight and dressing percentage were not affected by dietary CLA level ( $\mathrm{P}>0.05)$, which is in agreement with the results of Cordero et al. (2010). There were also no significant effects $(\mathrm{P}>0.05)$ of dietary CLA on the content of crude protein, ether extract and ash in the Longissimus dorsi muscle, but the dietary supplementation of CLA increased $(\mathrm{P}<0.05)$ dry matter content in $L$. dorsi muscle. Similar results are found by Migdal et al. (2004) where a significant increase in dry matter content in meat occurred in pigs fed 2\% CLA.

In this study, there was a numerically higher intramuscular fat content in the Longissimus dorsi muscle due to dietary CLA supplementation. Higher intramuscular fat content in $L$. dorsi has also been observed with dietary CLA supplementation (Joo et al., 2002; Martin et al., 2008). However, Bee (2001), Weber et al. (2006) and Corino et al. (2008) reported that CLA supplementation to pigs did not affect intramuscular fat content in pork. Although no significant influence of dietary CLA supplementation on intramuscular fat content was observed, the higher intramuscular fat content appeared to contribute to higher dry matter content in the L. dorsi muscle of the CLA groups.

The effects of dietary CLA on growth performance of the animals, carcass and meat quality were not completely consistent with other studies. This might be due to the differences in the genetics, the isomeric composition of CLA, the concentration and duration of supplementation of CLA, or CLA $\times$ genetic population interaction (Mersmann, 2002; Corino et al., 2003).

The effect of dietary supplementation of CLA on fatty acid composition of Longissimus dorsi muscle is presented in Table 3. The increase of dietary CLA level increased $(\mathrm{P}<0.05)$ concentrations of $\mathrm{C} 16: 0, \mathrm{C} 16: 1$ cis-9, C18:1 cis-12, CLAcis-9, trans-11, and SFA, and SFA/UFA proportion, and decreased concentrations of C18:1trans-9, C18:3n-3, C20:1 cis-11, C20:2n-6, and C20:4n-6, and UFA proportions. Moreover C16:0, C18:1cis-9, C18:1cis-11, SFA, UFA concentrations and SFA/UFA showed linear change with the increment of dietary CLA. Additionally, C18:2cis-9, cis-12 concentrations in CLA treatment groups were lower than in the control $(\mathrm{P}<0.05)$. Joo et al. (2002) mentioned that linoleic acid concentration in pork loin was significantly decreased by dietary CLA, possibly linoleic acid in pork loin was replaced by supplemented CLA. Besides, this might be due to CLA accelerating catabolism ( $\beta$-oxidation, etc.) of C18:2cis-9, cis-12 or inhibiting the deposition of $\mathrm{C} 18: 2$ cis-9, cis-12 as its isomers. However, the concentrations of C14:0, C18:0, C20:0 and monounsaturated fatty acids (MUFA) proportions were not affected by the dietary supplementation of CLA.

The Longissimus dorsi muscle in the CLA groups had higher SFA contents, but lower UFA content, resulting in a higher SFA/UFA ratio $(\mathrm{P}<0.05)$ than that of the control. The increase of dietary CLA level led to a linear increase in CLA 
Table 3. Effects of dietary CLA supplementation on fatty acid profiles in Longissimus dorsi muscle

\begin{tabular}{|c|c|c|c|c|c|c|c|c|}
\hline \multirow{3}{*}{ Fatty acid, \% } & \multicolumn{4}{|c|}{ Dietary treatments } & \multirow{3}{*}{ SEM } & \multirow{3}{*}{$\mathrm{P}$} & \multicolumn{2}{|c|}{ Contrasts } \\
\hline & \multicolumn{4}{|c|}{ CLA, \% } & & & \multirow{2}{*}{ linear } & \multirow{2}{*}{ quadratic } \\
\hline & 0 & 0.5 & 1.0 & 1.5 & & & & \\
\hline$\overline{\mathrm{C} 14: 0}$ & 2.04 & 2.16 & 2.31 & 2.60 & 0.259 & 0.478 & 0.132 & 0.756 \\
\hline C16:0 & $28.3^{\mathrm{b}}$ & $31.2^{\mathrm{ab}}$ & $31.9^{\mathrm{a}}$ & $32.5^{\mathrm{a}}$ & 1.018 & 0.039 & 0.008 & 0.274 \\
\hline C16:1trans -9 & 0.28 & 0.25 & 0.27 & 0.26 & 0.025 & 0.869 & 0.783 & 0.871 \\
\hline C16:1cis-9 & $3.78^{\mathrm{b}}$ & $4.96^{\mathrm{ab}}$ & $4.64^{\mathrm{ab}}$ & $5.78^{\mathrm{a}}$ & 0.522 & 0.089 & 0.025 & 0.972 \\
\hline $\mathrm{C} 17: 0$ & 0.16 & 0.17 & 0.19 & 0.20 & 0.017 & 0.402 & 0.108 & 0.729 \\
\hline $\mathrm{C} 17: 1 c i s-10$ & 0.11 & 0.11 & 0.11 & 0.14 & 0.017 & 0.481 & 0.290 & 0.268 \\
\hline $\mathrm{C} 18: 0$ & 11.8 & 12.5 & 13.5 & 12.2 & 0.640 & 0.305 & 0.458 & 0.143 \\
\hline C18:1trans -9 & $0.51^{\mathrm{ab}}$ & $0.56^{\mathrm{a}}$ & $0.48^{\mathrm{b}}$ & $0.49^{\mathrm{b}}$ & 0.019 & 0.034 & 0.106 & 0.290 \\
\hline C18:1trans-11 & 0.33 & 0.39 & 0.42 & 0.39 & 0.036 & 0.337 & 0.173 & 0.230 \\
\hline C18:1cis-9 & 31.1 & 33.1 & 29.7 & 29.5 & 1.602 & 0.391 & 0.279 & 0.492 \\
\hline C18:1cis-11 & 3.81 & 4.03 & 3.44 & 3.85 & 0.262 & 0.466 & 0.706 & 0.733 \\
\hline C18:1cis-12 & $0.20^{\mathrm{b}}$ & $0.28^{\mathrm{a}}$ & $0.20^{\mathrm{b}}$ & $0.26^{\mathrm{a}}$ & 0.018 & 0.015 & 0.228 & 0.753 \\
\hline C18:2cis-9,cis-12 & 13.6 & 7.86 & 9.56 & 8.55 & 2.330 & 0.325 & 0.209 & 0.319 \\
\hline $\mathrm{C} 20: 0$ & 0.16 & 0.16 & 0.14 & 0.16 & 0.015 & 0.581 & 0.579 & 0.627 \\
\hline $\mathrm{C} 18: 3 n-3$ & $0.26^{\mathrm{b}}$ & $0.35^{\mathrm{a}}$ & $0.25^{\mathrm{b}}$ & $0.23^{\mathrm{b}}$ & 0.022 & 0.007 & 0.098 & 0.021 \\
\hline $\mathrm{C} 20: 1 c i s-11$ & $0.36^{\mathrm{a}}$ & $0.20^{\mathrm{c}}$ & $0.27^{\mathrm{bc}}$ & $0.32^{\mathrm{ab}}$ & 0.026 & 0.002 & 0.763 & 0.001 \\
\hline CLAcis-9,trans-11 & $0.25^{\mathrm{b}}$ & $0.33^{\mathrm{ab}}$ & $0.5^{\mathrm{ab}}$ & $0.57^{\mathrm{a}}$ & 0.093 & 0.093 & 0.015 & 0.958 \\
\hline CLAcis-11,trans-13 & 0.08 & 0.10 & 0.13 & 0.16 & 0.037 & 0.492 & 0.133 & 0.854 \\
\hline CLAtrans-10,cis-12 & 0.06 & 0.09 & 0.18 & 0.18 & 0.040 & 0.106 & 0.020 & 0.805 \\
\hline CLAcc & nd & 0.03 & nd & 0.01 & - & - & - & - \\
\hline $\mathrm{C} 20: 2 n-6$ & $0.24^{\mathrm{a}}$ & $0.16^{\mathrm{b}}$ & $0.16^{\mathrm{ab}}$ & $0.18^{\mathrm{ab}}$ & 0.024 & 0.115 & 0.131 & 0.072 \\
\hline$C 20: 3 n-6$ & 0.24 & 0.10 & 0.14 & 0.15 & 0.042 & 0.182 & 0.227 & 0.111 \\
\hline $\mathrm{C} 20: 4 n-6$ & $2.32^{\mathrm{a}}$ & $0.94^{\mathrm{b}}$ & $1.45^{\mathrm{ab}}$ & $1.28^{\mathrm{ab}}$ & 0.434 & 0.172 & 0.196 & 0.174 \\
\hline Total CLA & 0.40 & 0.55 & 0.80 & 0.91 & 0.163 & 0.136 & 0.023 & 0.890 \\
\hline $\mathrm{R}$ & $0.11^{\mathrm{b}}$ & $0.25^{\mathrm{ab}}$ & $0.30^{\mathrm{a}}$ & $0.28^{\mathrm{ab}}$ & 0.056 & 0.115 & 0.041 & 0.177 \\
\hline SFA ${ }_{\text {trans } 10, \text { cis- } 12 / \text { cis-9, } \text {,rans }-11}$ & $42.5^{\mathrm{b}}$ & $46.2^{\mathrm{ab}}$ & $48.0^{\mathrm{a}}$ & $47.7^{\mathrm{a}}$ & 1.656 & 0.103 & 0.029 & 0.234 \\
\hline MUFA & 40.4 & 43.9 & 39.6 & 41.0 & 2.078 & 0.505 & 0.785 & 0.638 \\
\hline PUFA & 17.1 & 9.95 & 12.4 & 11.3 & 2.786 & 0.323 & 0.246 & 0.290 \\
\hline UFA & $57.5^{\mathrm{a}}$ & $53.8^{\mathrm{ab}}$ & $51.9^{\mathrm{b}}$ & $52.3^{\mathrm{b}}$ & 1.660 & 0.103 & 0.029 & 0.234 \\
\hline PUFA/SFA & 0.43 & 0.22 & 0.27 & 0.24 & 0.082 & 0.276 & 0.178 & 0.268 \\
\hline SFA/UFA & $0.75^{\mathrm{b}}$ & $0.86^{\mathrm{ab}}$ & $0.94^{\mathrm{a}}$ & $0.92^{\mathrm{ab}}$ & 0.055 & 0.094 & 0.026 & 0.233 \\
\hline$\Delta 9$ index & 0.46 & 0.46 & 0.43 & 0.44 & 0.015 & 0.370 & 0.176 & 0.848 \\
\hline
\end{tabular}

$\overline{a, b, c}$ means within a row with different superscripts are different $(\mathrm{P}<0.05)$; nd - not detectable $\mathrm{R}_{\text {trans-10,cis-12/cis-9,trans-11 }}$, ratios of the CLAcis-9, trans-11 to the CLAtrans-10, cis-12

CLAcc, CLAcis-8, cis-10; cis-9, cis-11, or cis-11, cis-13

Total CLA - the sum of CLA; SFA - saturated fatty acids; MUFA - monounsaturated fatty acids;

PUFA - polyunsaturated fatty acids; UFA - unsaturated fatty acids

cis-9, trans $-11(\mathrm{P}=0.015)$ and CLA trans -10 , cis $-12(\mathrm{P}=0.039)$. The total CLA content in the muscle showed a linear increase with increased dietary CLA level $(\mathrm{P}=0.023)$. The CLA concentration in the muscle of $1.5 \%$ CLA group $(0.91 \%)$ was more than two times of the control group $(0.40 \%)$.

The fatty acid profiles in the subcutaneous backfat are shown in Table 4. The dietary supplementation of CLA increased $(\mathrm{P}<0.05)$ the concentrations of C14:0, C16:0, CLA cis-9, trans-11, CLA cis-11, trans-13, CLA trans-10, cis-12, 
Table 4. Effects of dietary CLA supplementation on fatty acid profiles in backfat

\begin{tabular}{|c|c|c|c|c|c|c|c|c|}
\hline \multirow{3}{*}{ Fatty acid, $\%$} & \multirow{2}{*}{\multicolumn{4}{|c|}{$\begin{array}{c}\text { Dietary treatments } \\
\text { CLA } \%\end{array}$}} & \multirow{3}{*}{ SEM } & \multirow{3}{*}{$\mathrm{P}$} & \multicolumn{2}{|c|}{ Contrasts } \\
\hline & & & & & & & \multirow{2}{*}{ linear } & \multirow{2}{*}{ quadratic } \\
\hline & 0 & 0.5 & 1.0 & 1.5 & & & & \\
\hline$\overline{\mathrm{C} 14: 0}$ & $2.30^{\mathrm{b}}$ & $3^{\mathrm{ab}}$ & $2.98^{\mathrm{ab}}$ & $3.56^{\mathrm{a}}$ & 0.2747 & 0.039 & 0.007 & 0.814 \\
\hline C16:0 & $27.8^{\mathrm{b}}$ & $30.6^{\mathrm{a}}$ & $30.9^{\mathrm{a}}$ & $31.9^{\mathrm{a}}$ & 0.926 & 0.033 & 0.008 & 0.354 \\
\hline C16:1trans-9 & 0.39 & 0.31 & 0.35 & 0.33 & 0.031 & 0.281 & 0.370 & 0.280 \\
\hline C16:1cis-9 & 2.10 & 3.22 & 2.02 & 2.11 & 0.410 & 0.145 & 0.538 & 0.229 \\
\hline C17:0 & 0.24 & 0.25 & 0.29 & 0.29 & 0.025 & 0.345 & 0.108 & 0.926 \\
\hline C17:1cis-10 & 0.16 & 0.14 & 0.13 & 0.13 & 0.018 & 0.672 & 0.279 & 0.646 \\
\hline C18:0 & 15.27 & 14.7 & 17.4 & 16.7 & 1.225 & 0.366 & 0.201 & 0.950 \\
\hline C18:1trans-9 & 0.6 & 0.56 & 0.46 & 0.74 & 0.094 & 0.258 & 0.459 & 0.105 \\
\hline C18:1trans-11 & 0.55 & 0.55 & 0.83 & 4.64 & 1.658 & 0.294 & 0.113 & 0.266 \\
\hline C18:1cis-9 & $32.3^{\mathrm{a}}$ & $29.8^{\mathrm{ab}}$ & $26.2^{\mathrm{ab}}$ & $21.8^{\mathrm{b}}$ & 3.191 & 0.158 & 0.027 & 0.774 \\
\hline C18:1 cis-11 & $2.30^{\mathrm{ab}}$ & $2.90^{\mathrm{a}}$ & $1.97^{\mathrm{ab}}$ & $1.66^{\mathrm{b}}$ & 0.329 & 0.086 & 0.074 & 0.181 \\
\hline C18:1cis-12 & 0.14 & 0.17 & 0.17 & 0.15 & 0.021 & 0.568 & 0.647 & 0.199 \\
\hline C18:2cis-9,cis-12 & 12.7 & 10.9 & 12.0 & 11.1 & 1.077 & 0.604 & 0.442 & 0.660 \\
\hline C20:0 & $0.21^{\mathrm{a}}$ & $0.16^{\mathrm{b}}$ & $0.19^{\mathrm{ab}}$ & $0.17^{\mathrm{b}}$ & 0.012 & 0.046 & 0.109 & 0.167 \\
\hline C18:3n-3 & 0.40 & 0.47 & 0.51 & 0.50 & 0.061 & 0.584 & 0.228 & 0.569 \\
\hline C20:1cis-11 & 0.623 & 0.49 & 0.47 & 0.47 & 0.059 & 0.247 & 0.100 & 0.305 \\
\hline CLAcis-9,trans-11 & $0.65^{\mathrm{b}}$ & $0.81^{\mathrm{b}}$ & $1.44^{\mathrm{ab}}$ & $1.76^{\mathrm{a}}$ & 0.291 & 0.05 & 0.008 & 0.789 \\
\hline CLAcis-11,trans-13 & $0.12^{\mathrm{b}}$ & $0.12^{\mathrm{b}}$ & $0.28^{\mathrm{ab}}$ & $0.33^{\mathrm{a}}$ & 0.062 & 0.058 & 0.012 & 0.662 \\
\hline CLAtrans-10,cis-12 & $0.26^{\mathrm{b}}$ & $0.29^{\mathrm{b}}$ & $0.71^{\mathrm{ab}}$ & $0.88^{\mathrm{a}}$ & 0.160 & 0.032 & 0.006 & 0.679 \\
\hline CLAcc & $0.02^{\mathrm{b}}$ & $0.04^{\mathrm{b}}$ & $0.09^{\mathrm{ab}}$ & $0.14^{\mathrm{a}}$ & 0.029 & 0.043 & 0.006 & 0.574 \\
\hline $\mathrm{C} 20: 2 n-6$ & 0.47 & 0.42 & 0.43 & 0.43 & 0.050 & 0.877 & 0.563 & 0.654 \\
\hline$C 20: 3 n-6$ & 0.10 & 0.08 & 0.10 & 0.08 & 0.013 & 0.610 & 0.331 & 0.824 \\
\hline C20:4n-6 & 0.30 & 0.16 & 0.16 & 0.12 & 0.080 & 0.408 & 0.151 & 0.520 \\
\hline Total CLA & $1.06^{\mathrm{b}}$ & $1.26^{\mathrm{b}}$ & $2.53^{\mathrm{ab}}$ & $3.11^{\mathrm{a}}$ & 0.534 & 0.041 & 0.007 & 0.725 \\
\hline $\mathrm{R}_{t r}$ & 0.22 & 0.31 & 0.41 & 0.40 & 0.085 & 0.391 & 0.123 & 0.584 \\
\hline SFA & $45.7^{b}$ & $48.6^{\mathrm{ab}}$ & $51.7^{\mathrm{ab}}$ & $52.6^{\mathrm{a}}$ & 2.092 & 0.115 & 0.022 & 0.636 \\
\hline MUFA & 39.1 & 38.1 & 32.6 & 32.1 & 2.870 & 0.218 & 0.055 & 0.934 \\
\hline PUFA & 15.1 & 13.3 & 15.7 & 15.3 & 1.379 & 0.611 & 0.621 & 0.614 \\
\hline UFA & $54.2^{\mathrm{a}}$ & $51.4^{\mathrm{ab}}$ & $48.3^{\mathrm{ab}}$ & $47.4^{b}$ & 2.103 & 0.125 & 0.024 & 0.657 \\
\hline PUFA/SFA & 0.33 & 0.27 & 0.30 & 0.29 & 0.029 & 0.482 & 0.456 & 0.405 \\
\hline SFA/UFA & $0.86^{\mathrm{b}}$ & $0.95^{\mathrm{ab}}$ & $1.08^{\mathrm{ab}}$ & $1.14^{\mathrm{a}}$ & 0.079 & 0.098 & 0.016 & 0.836 \\
\hline$\Delta 9$ index & $0.44^{\mathrm{a}}$ & $0.42^{\mathrm{ab}}$ & $0.37^{\mathrm{ab}}$ & $0.31^{\mathrm{b}}$ & 0.039 & 0.126 & 0.021 & 0.679 \\
\hline
\end{tabular}

${ }_{\mathrm{a}, \mathrm{b}}$ means within a row with different superscripts are different $(\mathrm{P}<0.05)$ CLAcc, CLAcis8, cis-10; cis-9, cis-11, or cis-11, cis-13; total CLA - the sum of CLA; SFA - saturated fatty acids; MUFA - monounsaturated fatty acids; PUFA - poyunsaturated fatty acids; UFA - unsaturated fatty acids

CLAcc, total CLA, and SFA, and SFA/UFA proportion, and decreased the concentrations of $\mathrm{C} 18: 1$ cis-9, C18:1 cis-11, C20:0 and UFA proportions, whereas the concentrations of $\mathrm{C} 16: 1 \mathrm{n}-9, \mathrm{C} 18: 2$ cis-9, cis-12 and C18:3n-3 proportions were not affected. Furthermore, there were linear relationships between the dietary CLA level and the C14:0, C16:0, C18:1cis-9, SFA, UFA concentrations and SFA/ UFA.

The amounts of CLA cis-9, trans-11, CLA cis-11, trans-13, CLA trans-10, cis-12, CLAcc (cis8, cis-10; cis-9, cis-11, or cis-11, cis-13) and total CLA in the 
backfat linearly increased $(\mathrm{P}<0.05)$ with the dietary CLA level. The concentration of total CLA in the backfat (3.11\%) of $1.5 \%$ CLA group was more than two times $(\mathrm{P}<0.05)$ of the control group $(1.06 \%)$.

The overall effects of dietary CLA supplementation on fatty acid composition in the backfat were similar to that in Longissimus dorsi muscle. The CLA supplementation resulted in greater SFA contents in the backfat, but lesser MUFA and UFA contents $(\mathrm{P}<0.05)$, therefore higher SFA/UFA $(\mathrm{P}<0.05)$ ratios than those of the control group. Adding CLA to pig diets increased belly fat firmness associated with an increased ratio of SFA:UFA (Eggert et al., 2001). Soft bellies can cause some difficulty during processing, decrease appearance and shelf-life of retail products (NPPC, 2000). The increase of SFA:UFA ratio could be of certain practical significance from a pork processing point of view (White et al., 2008).

Furthermore, there were some differences in the responses of MUFA and polyunsaturated fatty acids (PUFA) between the backfat and the muscle to CLA supplementation, where MUFA exhibited a decreasing tendency $(\mathrm{P}=0.055)$ in the backfat with the increment of dietary CLA, and this phenomenon was not observed in the muscle. Meanwhile, we observed that PUFA content in the Longissimus dorsi muscle of the CLA groups was lower than that of the control group. Interestingly, unlike the $L$. dorsi muscle, the 1 and $1.5 \%$ CLA supplementation had numerically higher PUFA content in the backfat compared with the control group. Therefore the decrease of UFA in the backfat and muscle might be mainly attributed to the changes in MUFA and PUFA. Above results also showed that the effects of dietary CLA supplementation on MUFA and PUFA contents differed between the fat and the muscle. It might be ascribed to the differences of lipid metabolism between the two tissues. Further research is needed to explain the mechanism on an increase of PUFA content in backfat of pigs fed CLA.

Previous experiments observed that an inclusion of CLA in the diet increased CLA cis-9, trans-11, CLA trans-10, cis-12, and SFA contents and decreased MUFA and PUFA in both backfat and muscle of pigs (Martin et al., 2007; Cordero et al., 2010). In this experiment it was not observed that the decreases of MUFA proportion in the muscle and PUFA proportion in the backfat with CLA supplementation. This is not in agreement with the previous study by Martin et al. (2007).

The effect of the decrease in UFA, especially MUFA, might be related to the inhibition of $\Delta 9$ desaturase activity and mRNA expression by CLA. The $\Delta 9$ desaturase index has been used as an estimator of $\Delta 9$ desaturase enzyme activity (Korniluk et al., 2007). In this study, the $\Delta 9$ desaturase index, defined as ratio of (C16:1cis-9 + C18:1cis-9) to (C16:1cis-9 + C18:1cis-9 + C16:0 + C18:0), numerically decreased with dietary CLA supplementation in both the Longissimus dorsi muscle and backfat, and the $\Delta 9$ desaturase index for the backfat decreased linearly with the dietary CLA levels $(\mathrm{P}=0.021)$. However, the linear relationships 
differed between the backfat and the muscle, with regression coefficients of -0.0892 and -0.0187 (Figure 1), respectively, for the backfat and the muscle, illustrating a reason for different changes in MUFA between the two tissues.

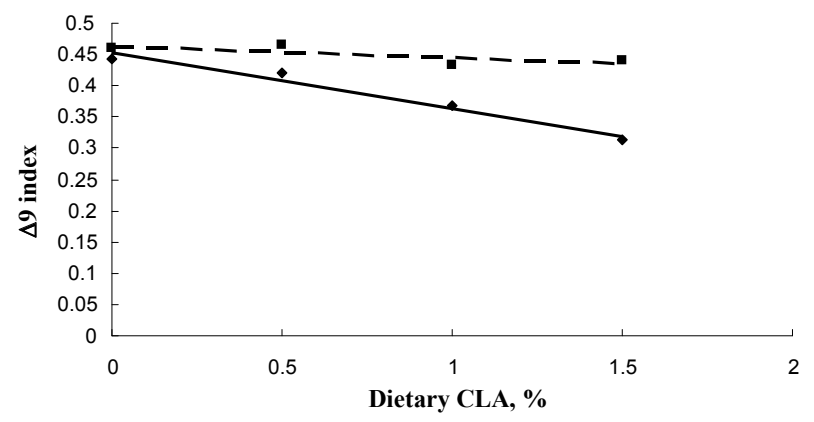

Figure 1. Linear response of $\Delta 9$ index in subcutaneous backfat (continuous line) and Longissimus dorsi muscle (doted line) to dietary CLA level. $\mathrm{X}=$ Dietary CLA\%. Subcutaneous backfat: C18:1n-9/C18:0 = -0.0892X + 0.4529, $\mathrm{R}^{2}=0.9706$; Longissimus dorsi muscle: $\mathrm{C} 18: 1 \mathrm{n}-9 / \mathrm{C} 18: 0=$ $-0.0187 \mathrm{X}+0.4637, \mathrm{R}^{2}=0.5936 ; \Delta 9$ index: $\Delta 9$-desaturase index $=(\mathrm{C} 16: 1$ cis $-9+\mathrm{C} 18: 1$ cis-9 $) /$ (C16:1cis-9+ C18:1cis-9+ C16:0 + C18:0)

For the modified fatty acid profiles in adipose and muscular tissues, the direct substitution effect of dietary source on fatty acids in the body is one likely reason. Moreover the modulation of gene expression and activity of lipogenic enzymes and $\Delta 9$ desaturase by CLA supplementation are likely another explanation. It has been demonstrated that CLA reduced acetyl-CoA carboxylase activity in the liver and adipose tissues of rabbits (Corino et al., 2002). Corino et al. (2003) also reported that CLA supplementation significantly reduced the acetyl-CoA carboxylase activity in adipose tissue of pigs. Several studies have shown that dietary CLA supplementation inhibited the expression and activity of hepatic $\Delta 9$ desaturase (Lee et al., 1998; Choi et al., 2000; Shang et al., 2005). These results suggest that CLA has an inhibitory effect on $\Delta 9$ desaturase activity. Therefore, the reduction in MUFA content was a reflection of decreased C18:1 content and increased abundance of saturated fatty acids in the tissues of pigs fed CLA, and might be a direct result of the decrease in the desaturase activity (Corino et al., 2003).

The amounts of CLA cis-9, trans-11, cis-11, trans-13, and trans-10, cis-12 in the Longissimus dorsi muscle and backfat showed linear increases with dietary CLA levels. Even so, the mean concentration of CLA in the backfat $(2.30 \%)$ was about three times of that in the $L$. dorsi muscle $(0.75 \%)$ for the CLA groups.

Moreover, though CLA-isomers, cis-9, trans-11 and trans-10, cis-12 had similar contents in the diet, and CLA cis-9, trans-11 was slightly lower than 
CLA trans-10, cis-12, a preferential incorporation of CLA cis-9, trans-11 was observed in this study. This phenomenon was also found by Thiel-Cooper et al. (2001) and Lauridsen et al. (2005). As shown in Figure 2, the responses of CLA isomers differed between the subcutaneous backfat and the Longissimus dorsi muscle. The concentrations of CLA isomers were lower in the Longissimus dorsi muscle than in the backfat. And CLA cis-9, trans-11 concentration was higher than CLA trans-10, cis-12 isomer in both the tissues. Both the isomers showed linear responses to dietary CLA supplementation.

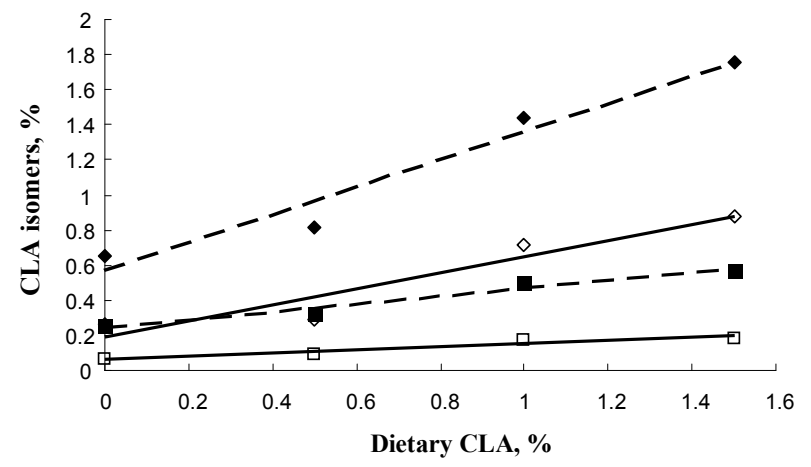

Figure 2. Linear response of CLAcis-9, trans-11 (doted line) and CLAtrans-10, cis-12 (continuous line) concentrations to dietary CLA levels in subcutaneous backfat $(\diamond, \diamond)$ and Longissimus dorsi muscle $(\square, \square),(\diamond),(\diamond),(\square),(\square)$ correspond to actual analysed values for subcutaneous backfat and Longissimus dorsi muscle, respectively. X - dietary CLA\%; subcutaneous backfat - CLAcis-9, trans $-11=(0.79 \pm 0.25) \mathrm{X}+(0.57 \pm 0.23), \mathrm{P}=0.0054, \mathrm{R}^{2}=0.955 ; \quad$ CLAtrans -10, cis $-12=$ $(0.45 \pm 0.14) \mathrm{X}+(0.19 \pm 0.13), \mathrm{P}=0.0043, \mathrm{R}^{2}=0.9097$

Longissimus dorsi muscle: CLAcis -9 , trans $-11=(0.22 \pm 0.08) \mathrm{X}+(0.25 \pm 0.07), \mathrm{P}=0.0108$, $\mathrm{R}^{2}=0.9692$ - CLAtrans-10, cis-12 $=(0.09 \pm 0.03) \mathrm{X}+(0.06 \pm 0.03), \mathrm{P}=0.0162, \mathrm{R}^{2}=0.911$

The ratios $\left(\mathrm{R}_{\text {trans }-10 \text {, cis-12/cis-9, trans-11 }}\right)$ of CLA cis-9, trans-11 to CLA trans-10, cis-12 in the subcutaneous backfat and Longissimus dorsi muscle of pigs fed the CLA diets were lower than the $\mathrm{R}_{\text {trans }-10 \text {, cis-12/cis-9,trans }-11}$ in the CLA compound that was added to the diets (i.e. 0.25-0.41 vs 1.07). Czauderna et al. (2004) also found the ratio of CLA cis-9, trans-11 to CLA trans-10, cis-12 in the liver of rats fed the diets enriched with CLA isomer mixture was lower compared with the ratio of these two isomers in the CLA isomer mixture (i.e. 0.712-0.833 vs 1.024). The accumulation rates of CLA cis-9, trans-11 and CLA trans-10, cis12 differed between backfat and Longissimus dorsi muscle in piglets fed 1\% CLA oil (Weber et al., 2006). As shown in Figures 3 and 4 there were linear 
relationships between CLA trans-10, cis-12 and CLA cis-9, trans-11 content in the $L$. dorsi muscle and the subcutaneous backfat. The deposition rate for CLA trans-10, cis-12 was only $42.1 \%$ of that for CLA cis-9, trans-11 in the L. dorsi muscle (slope $=0.421$ ), and $55.8 \%$ for the subcutaneous backfat (slope $=$ 0.5577). The results of linear responses of CLA trans-10, cis-12 and CLA cis-9, trans-11 might have a value in CLA application. The CLA trans-10, cis-12 and CLA cis-9, trans-11, these two CLA isomers, have been shown to exhibit a wide range of physiological properties in cell culture and biomedical studies with a potential to improve long-term human health.

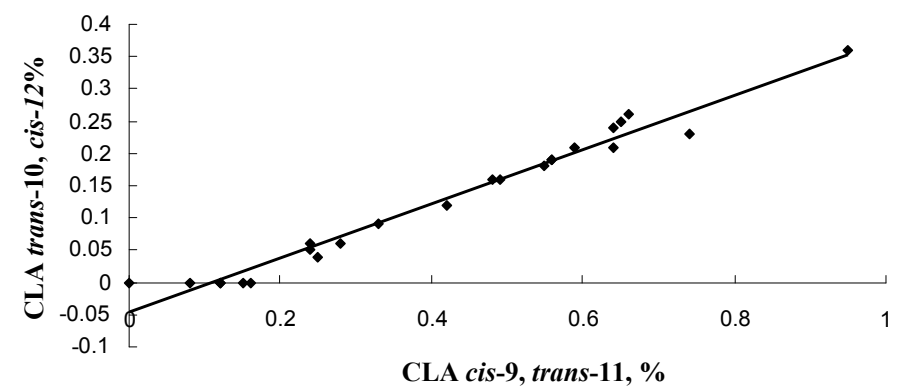

Figure 3. Linear relationship between CLAcis-9, trans-11 and CLAtrans-10, cis-12 contents in Longissimus dorsi muscle. CLAtrans-10,cis-12 $=(0.4209 \pm 0.01487) \mathrm{X}+(-0.04612 \pm 0.00712)$, $\mathrm{P}<0.0001, \mathrm{R}^{2}=0.9733$, where $\mathrm{X}-\mathrm{CLAcis}-9$, trans-11

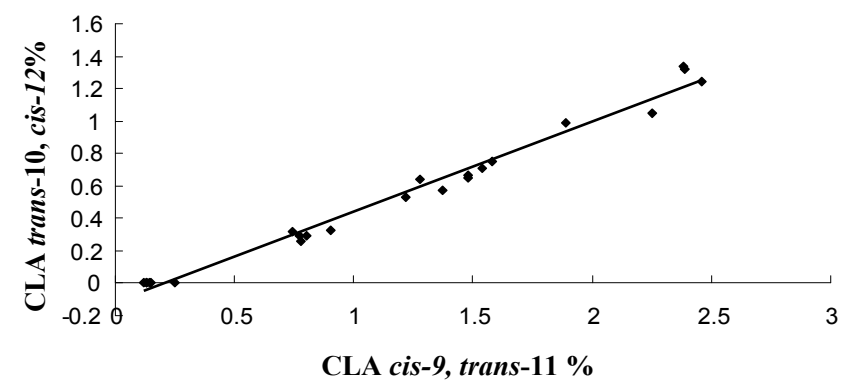

Figure 4. Linear relationship between CLAcis-9, trans-11 and CLAtrans-10, cis-12 contents in subcutaneous backfat. CLAtrans- 10, cis $-12=(0.5577 \pm 0.0158) \mathrm{X}+(-0.1165 \pm 0.0218), \mathrm{P}<0.0001$, $\mathrm{R}^{2}=0.9834$, where $\mathrm{X}-$ CLAcis -9, trans -11

In the nutritional management practice by feeding CLA to pigs in order to improve CLA content in pork products, a high level of supplementation (about 1 time of CLA cis-9, trans-11) of CLA trans-10, cis-12 should be considered, if we wish to have the same enrichment of both CLA trans-10, cis-12 and CLA cis-9, trans-11 in porcine meat and fat. 
The reason for the difference between CLA cis-9, trans-11 and trans-10, cis-12 content in tissues might be their dissimilar deposition efficiencies in pig. Czauderna et al. (2004) reckoned that CLA trans-10, cis-12 isomer is more efficiently driven through $\beta$-oxidation in cells of the muscles, kidneys, adipose tissue or liver of rats than their homologues. As for pigs, the varied deposition efficiencies of CLAisomers are possibly attributed to their variations in absorption, transportation and catabolism ( $\beta$-oxidation, etc.), or with competitive inhibition of CLA cis-9, trans-11 on CLA trans-10, cis-12 incorporation. Further study however, is needed to identify factors and precise molecular mechanisms of deposition and metabolism of CLA cis-9, trans-11 or CLA trans-10, cis-12.

\section{CONCLUSIONS}

The supplementation of diets with conjugated linoleic acid (CLA) did not notably affect growth performance, carcass characteristics, while it increased dry matter content in the Longissimus dorsi muscle in growing-finishing pigs. Furthermore, dietary CLA supplementation modified the fatty acid profiles in both the Longissimus dorsi muscle and backfat by increasing the concentrations of saturated fatty acids and decreasing the concentrations of unsaturated fatty acids, so the ratio of saturated fatty acids to unsaturated fatty acid increased. The CLA contents in the muscle and backfat increased in a CLA dose-dependent manner. The CLA cis-9, trans-11 and CLA trans-10, cis-12 displayed different deposition efficiencies in the muscle and backfat. Further studies should be undertaken to define the deposition mechanism of CLA isomers in pig tissues, and to determine the optimum CLA concentration in feed and time of feeding to achieve high CLA concentration in pig meat in a more economic way.

\section{REFERENCES}

AOAC, 2000. Association of Official Analytical Chemist, Official Methods of Analysis. $17^{\text {th }}$ Edition. Washington, DC

Azain M.J., 2003. Conjugated linoleic acid and its effects on animal products and health in singlestomached animals. Proc. Nutr. Soc. 62, 319-328

Bee G., 2001. Dietary conjugated linoleic acids affect tissue lipid composition but not de novo lipogenesis in finishing pigs. Anim. Res. 50, 383-399

Bhattacharya A., Banu J., Rahman M., Causey J., Fernandes G., 2006. Biological effects of conjugated linoleic acids in health and disease. J. Nutr. Biochem. 17, 789-810

Boles J.A., Kott R.W., Hatfield P.G., Bergman J.W., Flynn C.R., 2005. Supplemental safflower oil affects the fatty acid profile, including conjugated linoleic acid, of lamb. J. Anim. Sci. 83, 21752181 
Choi Y.J., Kim Y.C., Han Y.B., Park Y., Pariza M.W., Ntambi J.M., 2000. The trans-10,cis-12 isomer of conjugated linoleic acid downregulates stearoyl-CoA desaturase 1 gene expression in 3T3-L1 adipocytes. J. Nutr. 130, 1920-1924

Cordero G., Isabel B., Menoyo D., Daza A., Morales J., Pineiro C., Lopez-Bote C.J., 2010. Dietary CLA alters intramuscular fat and fatty acid composition of pig skeletal muscle and subcutaneous adipose tissue. Meat Sci. 85, 235-239

Corino C., Magni S., Pastorelli G., Rossi R., Mourot J., 2003. Effect of conjugated linoleic acid on meat quality, lipid metabolism, and sensory characteristics of dry-cured hams from heavy pigs. J. Anim. Sci. 81, 2219-2229

Corino C., Mourot J., Magni S., Pastorelli G., Rosi F., 2002. Influence of dietary conjugated linoleic acid on growth, meat quality, lipogenesis, plasma leptin and physiological variables of lipid metabolism in rabbits. J. Anim. Sci. 80, 1020-1028

Corino C., Musella M., Pastorelli G., Rossi R., Paolone K., Costanza L., Manchisi A., Maiorano G., 2008. Influences of dietary conjugated linoleic acid (CLA) and total lysine content on growth, carcass characteristics and meat quality of heavy pigs. Meat Sci. 79, 307-316

Czauderna M., Kowalczyk J., Niedźwiedzka K.M., Wąsowska I., Pastuszewska B., Bulska E., Ruszczyńska A., 2004. Liver and body mass gain, content of conjugated linoleic acid (CLA) isomers and other fatty acids in the liver of rats fed CLA isomers and selenium. J. Anim. Feed Sci. 13, 353-369

Eggert J.M., Belury M.A., Kempa-Steczko A., Mills S.E., Schinckel A.P., 2001. Effects of conjugated linoleic acid on the belly firmness and fatty acid composition of genetically lean pigs. J. Anim. Sci. 79, 2866-2872

Ha Y.L., Grimm N.K., Pariza M.W., 1987. Anticarcinogens from fried ground beef: heat-altered derivatives of linoleic-acid. Carcinogenesis 8, 1881-1887

Joo S.T., Lee J.I., Ha Y.L., Park G.B., 2002. Effects of dietary conjugated linoleic acid on fatty acid composition, lipid oxidation, color, and water-holding capacity of pork loin. J. Anim. Sci. 80, 108-112

Korniluk K., Czauderna M., Kowalczyk J., 2007. The influence of dietary conjugated linoleic acid isomers and high-selenized yeast on the fatty acid profile of spleen, pancreas and kidneys of rats. J. Anim. Feed Sci. 16, 121-139

Lauridsen C., Mu H., Henckel P., 2005. Influence of dietary conjugated linoleic acid (CLA) and age at slaughtering on performance, slaughter- and meat quality, lipoproteins, and tissue deposition of CLA in barrows. Meat Sci. 69, 393-399

Lee K.N., Pariza M.W., Ntambi J.M., 1998. Conjugated linoleic acid decreases hepatic stearoylCoA desaturase mRNA expression. Biochem. Biophys. Res. Commun. 248, 817-821

Martin D., Antequera T., Gonzalez E., Lopez-Bote C., Ruiz J., 2007. Changes in the fatty acid profile of the subcutaneous fat of swine throughout fattening as affected by dietary conjugated linoleic acid and monounsaturated fatty acids. J. Agr. Food Chem. 55, 10820-10826

Martin D., Muriel E., Gonzalez E., Viguera J., Ruiz J., 2008. Effect of dietary conjugated linoleic acid and monounsaturated fatty acids on productive, carcass and meat quality traits of pigs. Livest. Sci. 117, 155-164

Mersmann H.J., 2002. Mechanisms for conjugated linoleic acid-mediated reduction in fat deposition. J. Anim. Sci. 80, E126-E134

Migdal W., Pasciak P., Wojtysiak D., Barowicz T., Pieszka M., Pietras M., 2004. The effect of dietary CLA supplementation on meat and eating quality, and the histochemical profile of the $\mathrm{m}$. longissimus dorsi from stress susceptible fatteners slaughtered at heavier weights. Meat Sci. 66, 863-870

NPPC, 2000. Assessment Procedures for Pork Composition \& Quality. Natl. Pork Prod. Coun. Des Moines, IA 
NRC, 1998. Nutrient Requirements of Swine. National Research Council. $10^{\text {th }}$ revised Edition. National Academy Press. Washington, DC

Pariza M.W., 2004. Perspective on the safety and effectiveness of conjugated linoleic acid. Amer. J. Clin. Nutr. 79, 1132-1136

Ramsay T.G., Evock-Clover C.M., Steele N.C., Azain M.J., 2001. Dietary conjugated linoleic acid alters fatty acid composition of pig skeletal muscle and fat. J. Anim. Sci. 79, 2152-2161

SAS, 1999. SAS User's Guide Statistics. Version 6. SAS Institute Inc. Cary, NC

Schmid A., Collomb M., Sieber R., Bee G., 2006. Conjugated linoleic acid in meat and meat products: A review. Meat Sci. 73, 29-41

Shang X.G., Wang F.L., Li D.F., Yin J.D., Li X.J., Yi G.F., 2005. Effect of dietary conjugated linoleic acid on the fatty acid composition of egg yolk, plasma and liver as well as hepatic stearoylcoenzyme A desaturase activity and gene expression in laying hens. Poultry Sci. 84, 1886-1892

Tanaka K., 2005. Occurrence of conjugated linoleic acid in ruminant products and its physiological functions. Anim. Sci. J. 76, 291-303

Thiel-Cooper R.L., Parrish F.C., Sparks J.C., Wiegand B.R., Ewan R.C., 2001. Conjugated linoleic acid changes swine performance and carcass composition. J. Anim. Sci. 79, 1821-1828

Tischendorf F., Schone F., Kirchheim U., Jahreis G., 2002. Influence of a conjugated linoleic acid mixture on growth, organ weights, carcass traits and meat quality in growing pigs. J. Anim. Physiol. Anim. Nutr. 86, 117-128

Weber T.E., Richert B.T., Belury M.A., Gu Y., Enright K., Schinckel A.P., 2006. Evaluation of the effects of dietary fat, conjugated linoleic acid, and ractopamine on growth performance, pork quality, and fatty acid profiles in genetically lean gilts. J. Anim. Sci. 84, 720-732

White H.M., Richert B.T., Schinckel A.P., Burgess J.R., Donkin S.S., Latour M.A., 2008. Effects of temperature stress on growth performance and bacon quality in grow-finish pigs housed at two densities. J. Anim. Sci. 86, 1789-1798 